\title{
Value Pluralism and the Usefulness of Philosophical Theory for Public Administration
}

\section{Patrick Overeem' and Jelle Verhoef ${ }^{2}$}

\begin{abstract}
Taking stock of the DSF debate on value pluralism, this final contribution offers some (for now) concluding thoughts. It considers to which extent the original criticisms of the use of value pluralism by Spicer and Wagenaar can be maintained and which nuances should be added. Next, it discusses the use of philosophical concepts such as value pluralism for understanding administrative practice and developing administrative theory. It concludes this use can be considerable, provided such concepts are treated with sufficient carefulness.
\end{abstract}

\section{Keywords}

value pluralism, philosophical theory, administrative practice

\section{Debating Value Pluralism}

Real, fundamental debates are rare, even among academics. We are therefore very grateful for the opportunity offered by the editors of Administration \& Society to have another round of debate on value pluralism (VP) and its meaning for public administration. This debate, as usual, leaves something to

\footnotetext{
'Leiden University, The Hague, The Netherlands

2 Ministry of Security and Justice, The Hague, The Netherlands

Corresponding Author:

Patrick Overeem, Leiden University, Schouwburgstraat 2, The Hague, 25II VA, The

Netherlands.

Email: p.overeem@cdh.leidenuniv.nl
} 
be desired in terms of unity of theme and purity of tone. Overall, however, we think it has been lively, instructive, revealing, and important. May disputations like this be sine fine.

This final rejoinder consists of two parts. In the first, taking stock of the six contributions following upon our initial article (two by Spicer, two by Wagenaar, one by Talisse, and one by De Graaf), we return to our original claims and clarify to what extent we would like to maintain or nuance them. Doing so, we want to be not so much judges in our own case as defendants offering a last word on their behalf before the readers retract to form their own judgment. In the second part, we will briefly attempt to state more constructively what, in our opinion, VP can and cannot mean for administrative theory and practice. Thus, we answer the challenge to relate our ideas more to practice, while also discussing some of the pitfalls and benefits this debate has revealed for the employment of philosophical theory in a practically oriented field like public administration.

\section{Back to Our Claims}

Our article (Overeem \& Verhoef, 2014) intended to draw attention to a neglected topic. We observed that, while the work of Spicer, Wagenaar, and of course Weber have received ample attention in public administration, nobody in the field had, as far as we knew, seriously assessed their explicit use of, indeed reliance on, VP. ${ }^{1}$ This we found remarkable given the surge of attention for "public values" and "public value management" our field has seen in recent years (Van der Wal, Nabatchi, \& de Graaf, 2015; Williams \& Shearer, 2011). Somehow, the adoption of the philosophical concept of VP has gone unnoticed or, what is perhaps more likely, was uncritically accepted.

In our admittedly polemical article, we made the three-pronged argument that "the moral prescriptions for public administration" that Spicer and Wagenaar derive from VP "are neither logical (they do not follow), nor exhaustive (other implications are also possible), nor congruent (they do not match to each other)" (2014, p. 1004). These were our claims; do they still stand?

The first point, about logical entailment, was clearly the most important of our claims, taking the greater part of our argument. We wanted to make clear that (contrary to what Spicer and Wagenaar, in our reading, do) no particular behavior of public administrators and no particular design of public administration can be required simply because of VP. We feel particularly strengthened, after the debate, to uphold this claim. Especially Talisse's analysis has made it very clear, we think, that moral and practical prescriptions simply cannot be logically derived from VP alone as it is commonly understood by 
philosophers (notwithstanding the fact that, as Spicer notes, many of them have tried to do so).

Two nuances, however, seem in order. The first is the point, raised by Talisse too and indicated by the clauses "simply because" and "alone" just used, that certain prescriptions, although not entailed by VP itself, can be derived from sets of ideas of which VP is part. So when VP is combined with, for instance, liberal constitutionalism or a practice-oriented approach to administrative decision making, prescriptions can be derived from the resulting amalgam. But here, the add-ons do the prescriptive work, not VP. As Talisse aptly put it, many prescriptions that are not entailed by VP can still be consistent with it - including those of Spicer and Wagenaar.

Here it may be helpful to note in passing that in our article, we remained deliberately agnostic about the truth of VP. Whether VP is right or wrong, we did not and still do not clearly know. We want to assure our critics, however, that we do share many of the theoretical and practical commitments (other than VP) that they defend. So the conviction of the importance of politics and constitutionalism; the awareness of the imperfectibility of politics and the dangers of utopianism; the dislike of positivistic scientism that dominates present-day public administration; the insight that moral dilemmas permeate the daily work of public officials; the view that administrators, also in highly professionalized and even purely executive functions, are constantly making important moral judgments; the belief that this kind of work can never be fully grasped or managed by a set of rules - we share all these points. We only maintain that to hold them, one does not need to accept VP as well. As Talisse has made eloquently clear, a value monist can accept such positions, too. Indeed, one need not take any stance on the metaphysical nature of values to hold particular values dear, nor the same stance as others to hold the same values dear.

The second important nuance is that both Spicer and Wagenaar, pressed by our article, more or less deny that they ever wanted to logically derive any prescriptions from VP. They retort that their prescriptions came not from VP but from other ideas (especially Spicer) or that VP was never a starting point of any line of reasoning but only a description of the situation in which administrators find themselves (especially Wagenaar). To the extent that we have falsely ascribed a logical derivation mistake to them, we willingly acknowledge our misinterpretation of their work. Two characteristics of their replies prevent us from fully losing our worries, however. The first is that both authors continue to speak in terms of entailment. Thus, Spicer (2014) quotes his own statement that VP "at least implicitly for us, carries with it certain normative implications" (p. 1012) and Wagenaar refers to Chang's (1997) volume to uphold "the relationship between value pluralism ( . . .) 
with practical reason," implying there and elsewhere that because there is VP, administrators have to deal with it in a particular way. If not confused, such statements are at least confusing.

Our other, more general cause of concern is the contempt shown by our critics of logic and logical argument. Rather than absolving the logical error we ascribed to them or offering a clear alternative to repair it, they choose to blame us for suggesting their arguments were ever logical in the first place! This "don't bother us with your logic" mentality we find rather disturbing. It shows well the positive harm that logical positivism has done to our field and indeed the social sciences more generally: Because of its narrow and excessive reliance on logic next to empirical observation, many of its opponents have got an active dislike of the former if not also of the latter. This is all very unfortunate and unnecessary. Neither for us nor (we believe) for Talisse is logical validity the single criterion of good scholarship, but still we consider it one of the qualities one may reasonably demand from serious theoretical work.

On our two other claims (about exhaustiveness and congruence), we can be brief. All authors in the debate seem to agree that many different normative positions, including theoretically and practically incompatible ones, can go together with an acceptance of VP. Such differences may to some extent be due to, and legitimated by, circumstances of context, as Spicer (2014) supposes (pp. 1016-1017), but in many arguments about VP, including those by Spicer and Wagenaar, contextual factors play only a limited role. Indeed, VP is presented as a general moral truth recognized by many human beings. And so it should probably be, because if the implications of VP can differ and change radically depending on the circumstances in which it is held, it is hard to see how VP can still be a guiding moral notion and how it differs (as its adherents insist it does) from sheer relativism. Hence, we believe the multiplicity of incompatible positions related to VP does pose a problem for its adherents. It is unfortunate that Wagenaar and Spicer (unlike De Graaf) carefully avoid to engage with each others' (and Weber's) very different positions.

\section{Positive and Negative Implications}

Especially Wagenaar, but also De Graaf and to a smaller extent even Spicer, strongly believe VP is important not only as a philosophical concept to grasp something of our moral situation but also as a notion to better understand (and perhaps improve) administrative practice. It helps in particular, they suggest, to understand what public officials are doing and why, and how they experience their work. And they blame us for severing theoretical argument from administrative reality, ending up in sterile logical exercises without practical import, contributing nothing to the handling of concrete problems faced by administrators. 
To these rather unfair charges (expressing a no less exclusivist understanding of "proper" administrative theory than the position mistakenly ascribed to us), we would like to respond with a very concrete and important example: the trade-off, which has been and still has to be made by many governments in the world, especially since $9 / 11$, between security and privacy. This is of course a major issue that is experienced as a genuine value conflict in many ways and on many levels of government. Should governments be allowed to intrude upon the privacy of their own citizens and of foreigners, however innocent, by gathering data from email, phone calls, and other forms of communication to avert terrorist threats and prevent possible attacks? For politicians deciding upon legislation, and for intelligence officers working in this field, this is a recurring practical and morally laden question. It also seems a clear dilemma: On this issue, choosing more of one value inevitably means having less of the other, and there is no way to go around that.

Do we need the concept of VP to recognize and understand the value conflict here? Clearly not. As Talisse explains, the recognition (and experience) of a moral dilemma like this one is not something only value pluralists can have. Value monists such as Plato, Kant, Mill, and Dworkin, were they still alive, could also very well see and feel it. There is also no need to believe that security and privacy are incommensurable values. The whole dilemma seems not intrinsic to the values concerned but highly contingent upon an external factor, namely, the existence of dangerous terrorists who operate in a covert way. Would that somehow no longer be the case, the dilemma would immediately disappear. And so it is with many pressing dilemmas in political and administrative life.

What lessons can be drawn from our debate on VP for the wider topic of the use of philosophical theory in public administration? One thing we think we can readily agree upon is that arguments from authority- to the use of which we are all tempted-will not do. So the fact that Machiavelli and Weber, Berlin and Williams, Dewey and Rorty, or other respected authors did or did not endorse VP does not by itself demonstrate its truth. And the fact that one's opponent's premises "are contested by respected scholars within his own field" (Spicer, 2015) is no argument against those premises themselves. We should, in the famous words ascribed to Aristotle, love Plato but love truth more. Appeals to luminaries in the philosophical tradition can of course be made to clarify the terms of a substantive debate, as we have ourselves tried to do by our elaboration of Berlin's conceptualization of VP, but never to settle such a debate.

But philosophy can contribute more to administrative theory than mere conceptual clarification. As Spicer rightly notes (2015), philosophical reflection and argumentation can raise our awareness and understanding of a special kind of intractable problems that we would not see or grasp 
otherwise- "philosophical questions ( . . . ) that, in the final analysis, cannot be settled by the methods of either science or logic." Contrary to the impression our initial article may have given, we fully acknowledge the existence and importance of such questions. Indeed, we think questions about the nature, (in)compatibility, and (in)commensurability of values are precisely of this kind. In this sense, as we noted at the end of our initial article, the concept of VP is highly important for diagnostic purposes. The VP thesis can (even if metaphysically untrue!) help raise our awareness of the "moral scarcity" that seems to characterize the world we inhibit. In this limited respect we agree with De Graaf (2015), that VP, although prescriptively barren, can be "highly relevant for administrative practice." To say, however, that our moral situation should be ameliorated in a particular way, or even to evaluate it as problematic, is something that VP, on its own, does not entail.

The imprecise use of VP by prominent administrative theorists and the uncritical acceptance of that use by the wider public administration community is, we think, somewhat symptomatic for our field as a whole. While aspiring to be interdisciplinary, it is still quite eclectic; interesting ideas and findings from other fields are imported, used, and occasionally showcased, but too often not fully integrated or even grasped. This is not only the case for contributions from philosophy but also for those from much closer disciplines like law, management studies (and economics), and even political science (Wright, 2011). Ideas from philosophy, however, are especially vulnerable to sloppy use and even abuse, because philosophy is less known to most public administration colleagues than the other fields mentioned and because philosophical ideas are often taken as more malleable than seemingly "harder" findings from those fields.

This is not to deny that (moral) philosophy can be fruitfully connected to the practically oriented field of public administration. Here we fully concur with Spicer, who has claimed before and does so again in this volume, that philosophy is indeed of crucial importance to administrative scholarship and practice. It should, however, be resorted to with greater carefulness and, indeed, more logical validity than has been done so far in the writings on VP that we have criticized. If not, the field of public administration might fall victim to its own Sokal hoax.

\section{Declaration of Conflicting Interests}

The author(s) declared no potential conflicts of interest with respect to the research, authorship, and/or publication of this article.

\section{Funding}

The author(s) received no financial support for the research, authorship, and/or publication of this article. 


\section{Note}

1. The relationship between Weber's political and administrative theory, on the one hand, and his value pluralism (avant la lettre), on the other, is, however, rather implicit and unclear (but see Spicer, 2015a).

\section{References}

Chang, R. (Ed.). (1997). Incommensurability, incomparability, and practical reason. Cambridge, MA: Harvard University Press.

de Graaf, G. (2015). The bright future of value pluralism in public administration. Administration \& Society. Advance online publication. doi:0095399715598346

Overeem, P., \& Verhoef, J. (2014). Moral dilemmas, theoretical confusion: Value pluralism and its supposed implications for public administration. Administration \& Society, 46, 986-1009.

Spicer, M. W. (2014). In defense of value pluralism in public administration. Administration \& Society, 46, 1010-1019.

Spicer, M. W. (2015). Public administration in a disenchanted world: Reflections on Max Weber's value pluralism and his views on politics and bureaucracy. Administration \& Society, 47, 24-43.

Van der Wal, Z., Nabatchi, T., \& de Graaf, G. (2015). From galaxies to universe: A cross-disciplinary review and analysis of public values publications from 1969 to 2012. The American Review of Public Administration, 45, 13-28.

Wagenaar, H. (2014). The necessity of value pluralism in administrative practice: A reply to Overeem. Administration \& Society, 46, 1020-1028.

Williams, I., \& Shearer, H. (2011). Appraising public value: Past, present and futures. Public Administration, 89, 1367-1384.

Wright, B. E. (2011). Public administration as an interdisciplinary field: Assessing its relationship with the fields of law, management, and political science. Public Administration Review, 71, 96-102.

\section{Author Biographies}

Patrick Overeem is an assistant professor at the Institute of Public Administration, Leiden University, the Netherlands. His areas of research include political philosophy, administrative ethics, the constitutional legitimacy of public administration, and political-administrative relations. His work has appeared in Administration \& Society, Public Administration Review, and Administrative Theory \& Praxis, among others.

Jelle Verhoef is a former management consultant and currently a civil service trainee at the Dutch Ministry of Security and Justice, The Hague. He took degrees in both Political Science and Public Administration, and did research on value pluralism in administrative theory. 